\title{
The co-evolution of taxi drivers and their in-car navigation systems
}

\author{
Fabien Girardin Josep Blat \\ Universitat Pompeu Fabra, Interactive Technologies Group \\ Passeig de Circumvalació 8, 08003 Barcelona, Spain \\ \{Fabien.Girardin, Josep.Blat\}@upf.edu
}

\begin{abstract}
In the recent years, the massive use of in-car navigation systems has symbolized the emergence of location-based services for wayfinding. This market success creates the opportunity to learn from a realworld use of present location-aware systems in order to inform the design of future applications. In that context, we are using an ethnographic approach to study the different ways taxi drivers rely on their navigation system. First, this work focuses on describing how location technologies impacted the wayfinding practices and similarly how the practice influences the appropriation of navigation systems. This co-evolution starts from the acquisition and setup of a navigation system to mastering the system shortcomings and limitations. Second, we study the criteria that steer a driver in selecting among the different modes of a navigation system and the other artifacts and tools (e.g. maps, street directories, landmarks) he or she uses for location awareness and wayfinding. Moreover, we are analyzing the role of context in this dynamic. That is where and when a driver accesses location information from the system, the external supports and the surrounding environment. We present the findings that emerged from 12 interviews augmented by in-car observations. The study concentrates on the taxi drivers of the city of Barcelona, Spain. This community forms a massive population of early adopters of in-car navigation systems with a strong past practice of relying on mobile technologies and maps to support their work.
\end{abstract}

Keywords: Satellite navigation systems, socio-technical gap, human-computer interaction, coevolution

\section{Introduction}

The recent popularization of in-car navigation systems (sat-nav) was made possible by the maturation of Global Navigation Satellite Systems (GNSS) in conjunction with constant improvements of hardware (processing powers, screen size and resolution) embedded in navigation systems, and advances in the collection and visualization of geographic information. These technological advances met a need of drivers to augment their knowledge of the space and support their wayfinding practice. In Japan, where the technology has been available for ten years, over 3.5 million vehicles have systems installed. A recent technology market research study revealed that one in six (17\%) U.S. adults currently own or use a GPS location device or service, $33 \%$ of them use it in their vehicle (Harris, 2007). This extensive distribution of satellite navigation systems represents the first massive adoption of location-aware system by the public. However, the market success also translates into issues of poor integration of the technology into the practice of driving. For instance, in the late nineties the Japanese transport ministry began to identify accidents caused by drivers distracted by their route guidance displays. To overcome these types of problems, everyday users of satellite navigation systems not only adapt to their systems, they also adapt their systems to their needs. They create a co-evolution cycle observed and theorized in multiple contexts of human-computer interaction (O'Day et al., 1996).

The designers of new technologies, such as location-aware systems, navigate a delicate balance between prediction of how novel technologies will serve a real human need and observation of authentic use and subsequent coevolution of human activities and novel technologies. However, due to the lack for real real-world deployment of location-aware system there has been little research published from an end-user perspective in the research community. In this paper we take the opportunity of the market success of satellite navigation systems to observe how positioning technologies integrate into already existing practice and how this practice influence the use of the 
technology. Our aim is to provide evidences of the importance of the context and the situations that determine the use of the system. Ground on situated action theory (Suchman, 1987), we analyze activities not as isolated events, but situated within a context which informs their sense and their character.

We collected these contextual evidences through ethnographic techniques. The study took place among the community of taxi drivers in the city of Barcelona, Spain. This community forms a massive population of early adopters of in-car navigation systems with a strong past practice of relying on mobile technologies and maps to support their work. The collection of observational notes and focused four aspects of the coevolution depicted in Table 1.

\begin{tabular}{|l|l|}
\hline Aspect & Description \\
\hline Acquisition & $\begin{array}{l}\text { Why and how does this new technology get integrated among } \\
\text { other artifacts, and how satellite navigation systems impacted the } \\
\text { use of these artifacts. }\end{array}$ \\
\hline Gap in expectation & \begin{tabular}{l} 
Understand if the reasons to adopt are matched in practice. \\
\hline Appropriation
\end{tabular} \\
$\begin{array}{l}\text { How much the system can be trusted and what is the reaction } \\
\text { when th quality is not met (awareness of the } \\
\text { limitations/imperfections). Importance of the knowledge of the } \\
\text { urban environment. }\end{array}$ \\
\hline Access to the geoinformation & $\begin{array}{l}\text { What kind of geoinformations are used by the drivers both from } \\
\text { the system and from the environment (experience, radio, interaction } \\
\text { with customer, context such as visibility to landmarks). }\end{array}$ \\
\hline
\end{tabular}

Table 1. Aspects of coevolution studied

In response to some of these interrogations we illustrate how location technologies is changing the ways cab drivers work in Barcelona. This knowledge could used in to inform on the future design of location-aware systems.

In the reminder of this paper, we first present works related to the study of the appropriation of mobile and positioning technologies. Then we analyze our observations with a division in four main categories. Finally, we draw some implication in these findings into the design of future location-aware systems.

\section{$2 \quad$ Related Works}

Much of the research on location-aware systems and mobility has dealt with technical issues such as limited battery life, unreliable network connections, varying channel coding, volatile access points, risk of data loss, portability, and location discovery. Technological limitation impairs the quality of the information delivered. These limitations impact the overall quality of the system. For instance, in a survey only $15 \%$ of participants thought that routing instructions generated by their navigation systems were always completely reliable (Forbes, 2007). On that matter, another strand of research focus on the delivery of location and wayfinding information (Look et al. 2005) and its proper visualization (Suomela \& Lehikoinen, 2004).

However these design research do not take into consideration the integration of these techniques into the user's practices. User centered research on mobile work enhanced by location-aware systems has now recently emerged. This type of research aim at understanding the role of technology and artifacts in mobile work and identify the opportunities for the development of appropriate technological solutions to support mobile workers (Perry et al., 2001). In the context of satellite navigation systems, has been pursued with the collection of survey data. Forbes \{ref\} performed a study on in-vehicle navigation system usage and driving behavior patterns. The 
results show for instance that although navigation system users frequently use their systems in an active manner when traveling in unfamiliar environments, there is a clear tendency to use the system actively less frequently when traveling in familiar environments (where drivers have the benefit of local knowledge).

These type of empirical evidences are delicate to collect because of the lack of subjects to observe. This is the reason the study of taxi drivers is relevant. Indeed, in some countries the use of computers in taxis has been a common sight for many years (Skok, 1999). In a longitudinal ethnographic study with empirical data provided by qualitative interviews of driver behavior to highlight some issues of the relationships between the drivers practices and the supporting mobile technology (Elaluf-Calderwood \& Sørensen, 2006). In concordance with the purpose of this paper, she points out that the most interesting technological opportunities may be thwarted by practical barriers such as problems with support of individual taxi work through GPS systems when these assume the driver relinquish control entirely and simply follow directions when these are far from perfect.

However this work focused on the role of technologies to dispatch taxi drivers and the search for customers in London rather than not on their wayfinding practices supporting by satellite navigation systems. The following section introduces our method to collect evidences of the coevolution of taxi drivers and their satellite navigation system

\section{Method}

The research approach is based ethnographic methods (Crabtree, 2003) that can be characterized as 'ethnomethodologcal', an analytic approach that has evolved over time under the auspices of the radical studies of work program (Garfinkel \& Wieder 1992) or, more simply, studies of work. The study was not design to provide a complete survey of taxi practice and was intended to be interpretive rather than statistical. In an interpretative study, the researcher does not try impose his or her own previous understanding onto the situation. Thus we discuss and examine usepractices and situated activities. We study of how the systems are used by taxi drivers and not on how the systems work (e.g. interfaces, mobile antennas, software, hardware).

In order to collect rich and detailed information, we felt it was important to gather many different kinds of situated data, and to gain our understanding, as far as possible, from observation and interviews in the actual work settings. Interviews alone did not suffice, as people are necessarily selective in what they describe or think is important to discuss. The solution involved using a combination of qualitative interviews and analysis of the artifacts used at work. We collected data from 12 taxi drivers with a working experience from 2 years to 20 years. The interviews were conducted at the Barcelona airport parking lot dedicated to taxis. This site provided a good setting to get in touch with taxi drivers, because they often must wait there for more than 30 minutes. During this period, they fill the time discussing, playing (e.g. chess, scrabble, golf), cleaning their care and eat. Interviews were complemented by situational insights from observation of driver behavior while driving. 

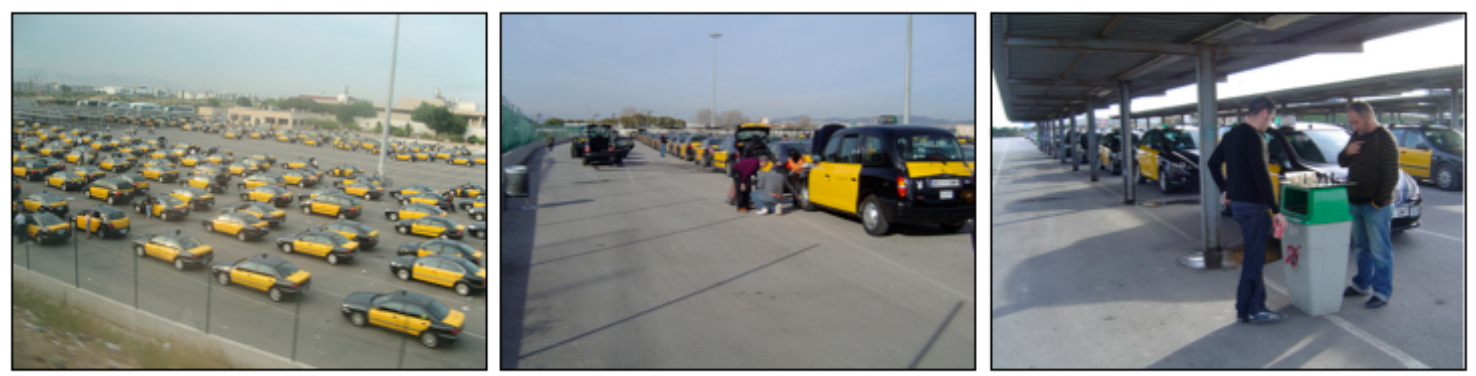

Figure 1. Waiting area at the Barcelona airport. Classic activities revolve around fixing or cleaning the taxi, sleeping, reading, eating and playing

\section{$4 \quad$ Findings}

With no surprise, there was a diversity in the appropriation of the technology of their sat-nav system to accomplish their work among the 12 taxi drivers in this study. The participants in this study approached in many different ways. For instance, in the pre-study, one driver was uniquely using his satellite navigation system as speedometer. Rather than consider each of these kinds of approach in turn, we sought to identify common themes or features in the evolution that bound them together. We discovered four three finding about the way in which a satellite navigation system in conjunction with other artifacts were used by taxi drivers to improve their practice and wayfinding techniques.

These three topics are used to explore key notions of co-evolution, how taxi drivers appropriate the technology, how it affects their practice, how the practice influence the use of the system and how this takes place over time. While other authors have discussed some of these findings in some form or other, we attempt to explore the issue surrounding them. We demonstrate how these activities evolve over time. In the sections that follow we consider each key finding in turn.

\subsection{An eco-system of artifacts}

The navigation system completes an arrangement of artifacts proving layers of information of the city. Our observations detected the dispatched radio, newspaper, paper of points of interests, the "Guia" and mobile phones (Table 2). In several aspect the satellite navigation system modified the process a driver gets an understanding of the location of the destination. In the past, the driver would open the "Guia" and browse the index of streets and points of interest to get access to a map of the area comprised by the destination.

\begin{tabular}{|l|l|l|}
\hline Artifacts & Purpose & $\begin{array}{l}\text { Context of use for } \\
\text { wayfinding }\end{array}$ \\
\hline Satellite navigation system & $\begin{array}{l}\text { Inform on the whereabouts, } \\
\text { provide directions to } \\
\text { destination }\end{array}$ & See section 4.4 \\
\hline "Guia" & $\begin{array}{l}\text { The "Guia" is a dense book of } \\
\text { all the streets and POI in } \\
\text { Barcelona Locate the } \\
\text { destination, find references, } \\
\text { locate points of interests and } \\
\text { hotels. }\end{array}$ & $\begin{array}{l}\text { At the start of the journey to } \\
\text { locate theighborhood. }\end{array}$ \\
\hline Dispatched radio & $\begin{array}{l}\text { Receive jobs from the central. } \\
\text { Can be audio or text }\end{array}$ & $\begin{array}{l}\text { In rare situations when the } \\
\text { driver gets lost. }\end{array}$ \\
\hline Newspaper & Provide updated information & During breaks \\
\hline
\end{tabular}




\begin{tabular}{|l|l|l|}
\hline & on the city & \\
\hline Mobile phone & $\begin{array}{l}\text { The mobile phone often } \\
\text { available is seen as a social } \\
\text { link to family and friends, and } \\
\text { is very rarely used as a tool to } \\
\text { support their work. One driver }\end{array}$ & $\begin{array}{l}\text { In the rare situations when } \\
\text { the diver gets lost. Currently } \\
\text { the ispatching orders and } \\
\text { professional questions (e.g. } \\
\text { told me that he used it a few } \\
\text { times to check if a table was } \\
\text { available at a restaurant for } \\
\text { some destinations). } \\
\text { clients rates for } \\
\text { foreigners). This is a service } \\
\text { he gives as added value, but he } \\
\text { "normally should not do it". }\end{array}$ \\
\hline Notes & $\begin{array}{l}\text { Store information on informal } \\
\text { destinations of the city that are } \\
\text { not present in the guia and in } \\
\text { the navigation system }\end{array}$ & $\begin{array}{l}\text { To keep track of specific } \\
\text { destinations and opening }\end{array}$ \\
\hline
\end{tabular}

Table 2. The eco-system of artifacts that taxi drivers use in the wayfinding
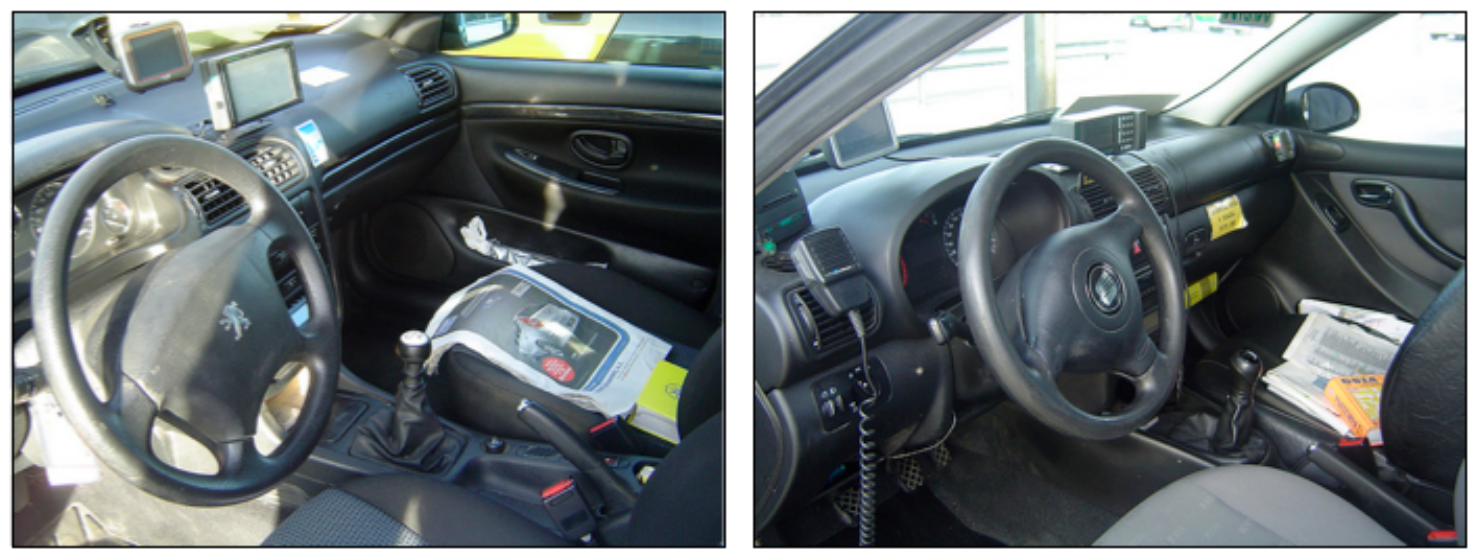

Figure 2. Artifacts for wayfind in the taxi in Barcelona. Dispatched radio (audio or text), satellite navigation system, newspaper, paper notes and the Guia.

Satellite navigation systems has two main modes. In the passive mode the system mainly provides a sense of orientation and situation awareness. The active navigation system can be defined as occasions where the destination is entered. The system may provide routing advice, turn by turn guidance and traffic information. Some drivers to keep the system in passive mode at any time. to keep track of the radars (a priority for experienced drivers) and to keep an awareness of where they are (keep track of the proximate streets is important for inexperienced drivers) and it was also very valuable to learn the city.

\subsection{Acquiring tranquility}

The biggest moments of uncertainty for taxi drivers, take place when a journey take the to a village or unknown neighborhood of Barcelona, such as the multiple suburban business areas that emerged from the ground in the recent years. In consequence there is a consensus that a satellite navigations system is an unbeatable tool when it come to reaching a specific destination in a village and leaving it. It is a strong reason for purchase. But it is not really to be more productive 
and hence earn more, rather than feeling more serene. A tool not to make more money, nor to improve the efficacy, but to tranquilize, "I can go everywhere" and relax. In passive mode they can forget about the names of the streets and the intersection because he could always fallback on his real-time position and act based on that. Yet, the old practice to count the number of the streets from a known intersection did not completely disappeared.

Some drivers mention that it does not only tranquilize them but also their clients "they know I cannot cheat them with it", "it reassures them that I go to the proper destination". For experienced drivers, they now know that they have a "companion" (some refereed to their car with an affectionate "she" and their sat-nav with a "he") can take them anywhere and avoid these moment when they had to search endlessly browsing the street directories of the suburbs of Barcelona, asking their colleagues via radio or mobile phone. One mentioned me that "the fear of getting lost with a client I felt in my stomach now disappeared". Another was relieved that he did not have to use his radio to ask colleagues about particular location information and wayfinding (even though many taxi drivers are extreme social animals).

However, the less experience drivers are confronted to system imperfections (inaccurate maps, data not updated). The same kind of errors an experienced driver would overcome. This observation goes in the direction as Elaluf-Calderwood \& Sørensen (2006) on the feeling of relaxation that the technology brings "when the destination is known and pressure of constantly searching for new passengers is reduced by greater trust place in the computer system) but also the distraction it brings to their driving (multiple-tasking, they liked the fact that the system turns off to black screen after two minutes idle) and the accuracy of the GPS system used (billing and payment, outages, when it needs repair it means unplanned time of the road)".

\subsection{Knowledge of the city}

There are different appropriation of the location-aware system depending on the overall knowledge and experience of the space. In the context of the city, as opposed to the suburbs and villages, practices differ and the "Guia" comes into play. Experienced drivers have been using it all their professional lives and have partially learned the city with it. Another big part of the knowledge drivers acquire come from the clients themselves. They know all the tricks and secrets official books and commercial systems can't tell. As the experience drivers contain most of the knowledge of the city in memory they rarely return to the Guia. In fact, they prefer using their sat-nav and hit the Guia only as fail-over (e.g. when the system does not contain a street number or lacks of information). Even after 20 years of experience, one drivers still perceived accessing the Guia as a demanding task. Compare to that, hitting the screen of his Tom-Tom was a pure pleasure.

This process of accessing correct information is executed differently by less experienced driver. First, they had mixed feelings about their experience with their sat-nav "It is like my mobile phone, sometimes it does not work well", "it is a potential problem" in terms of quality of services and precision of the information. Their demand of accurate information quickly reached the limits of the systems and the inaccuracy of the system directly impacted the quality of their service (mostly because they had to deeply rely on it in the beginning). In consequence, they embraced the use of the "Guia" which is "more accurate and complete" (particularly when it comes to providing a detailed index of streets, points of interest and city-related information). In the city, they learned not to completely rely on their sat-nav (because it is hard for them to judge if the information is erroneous or not) and have a tendency to first open the "Guia". One told me that he learned to interpret the system and its errors. When a conflict emerges between his sat-nav and his intuition he starts to "improvise". Depending on the circumstances he would either switch it off or ignore it for a while. 
This need by less experience drivers to access multiple sources of information in their wayfinding break the myth that sat-nav system changes a "skilled" job unto a unskilled one (ref to Sylvia). On this point, an experienced driver explained that inexperience drivers who use a navigation system do not gain knowledge of the city, because they follow the recommendations and "stop to think". My contact with the younger generation proved somehow the opposite. They are eager to learn the city and the imperfection of their systems forced them to get knowledge from the "Guia" and from the clients.

As drivers could not completely rely on the system, they had to create an in-depth knowledge of the city to improve quality of service and relax. Means to gain knowledge on the city translated into leaving the satnav system in passive mode to learn the street names. As a consequence, after installation, the system tends to be used less and less by cab drivers.

\subsection{Going, arriving and leaving}

The wayfinding practice takes place in 2 main stages. There is a separation difference between "to go" and "to arrive" and the location information are different in each phase.

During the journey to a rather unknown destination, drivers seem to accesses the geospatial information as in a "funnel". First, there is a tendency to quickly checks in the paper-based guide of the city to know more or less the area he should direct to. If the paper map does not provide enough information such as reference points to precisely arrive at the area, the driver will engage with the navigation system. In that area, he waits for a traffic light to type the exact address in the navigation system. If the driver knows he will have to go on the highway directly, he/she will check prior to leaving. He explained that he engages with the system at that moment to avoid the often misleading information on the path to take. Indeed, a taxi driver applies several paths depending on the time of the day and circumstances (e.g. traffic, weather conditions, recommendation of passenger). In fact, this specific taxi driver could name me the places where he experienced the navigation information to be absolutely irrelevant (e.g. get access major squares). This scenario do not take place with the most experienced taxi driver, who find the Guia as the waste of time and strongly rely on their navigation system.

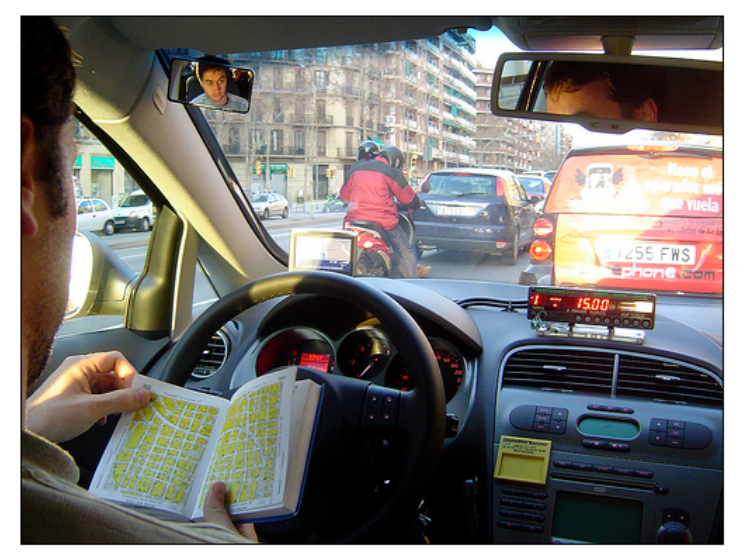

Figure 3. . Use of the "Guia" at a stop when approaching to destination

A big problem for a taxi driver is to be lost after dropping off a customer. This often happens when the customers guide to the destination. Therefore, taxi drivers thrive on information to get back into known territory. That can be landmarks (e.g. a tall building), the topology (e.g. a mountain/hill). But getting a sense of orientation can easily become problematic (e.g. during 
nighttime or bad weather conditions when tall buildings and mountains are not clearly visible). This is where the sat-nave comes handy. This specific taxi driver would ask the them to give him the way out by typing "Plaza Espana" (i.e. a large roundabout in the center of Barcelona). To get out of the unfamiliar environment, the driver would be either very cautious in the path taken to enter the area ("I am a very good observer") or use their sat-nav with destination Barcelona. In their exit strategy, their reach their bookmark of saved destinations are hit "home", "Barcelona, any street", or "Barcelona center".

\section{Conclusions}

This paper has not aimed to do a theoretical review of the design parameters used in the design of satellite navigation systems, neither to describe state of the art system but to analyse how everyday taxi drivers integrate (adapt?) location-aware system into their practice and how the systems impact the practice. Only part of the empirical work completed has been presented. There is still a considerable amount of data to be analyzed under the socio-technical lenses explained in the introduction of this document.

This studies brings more evidences that we adapt resources in the environment to our needs. Our culture will adapt itself or the limitations of the technology, so the technical limitations are not important Ackerman, M. S. (2000). Yet the description of this first-order approximation that satnav systems represent in the context of location-aware computing and discusses how we could go beyond based on the evidences of co-evolution. We aim to describe the social implications of technologies will often come after people invent new, unforeseen, uses of these technologies (Abowd and Mynatt, 2000).

The few mistakes a sat-nav system can make challenges the trust novice cab drivers put in the location technology. In fact, they have a tendency to use the street directory and paper maps for the dense urban area (or areas where they have points of reference). Experience drivers mention their feelings that now even freshly arrived cheap labor could do their job (as mentioned by Silvia). The reality proved to be more complicated than that. A sat-nav system does only do a part of the taxi driver's job. It fails to supports their need of granularity necessary for a journey.

\section{References}

Ackerman, M. S. (2000). The intellectual challenge of cscw: The gap between social requirements and technical feasibility. Human-Computer Interaction, 15(2/3):181-203.

Abowd, G. D. and Mynatt, E. D. (2000). Charting past, present, and future research in ubiquitous computing. ACM Trans. Comput.-Hum. Interact., 7(1):29-58.

Carroll, J. M., and M. B. Rosson. "Deliberated Evolution: Stalking the View Matcher in Design Space". Human-Computer Interaction, Vol. 6, 281-318, 1991

Crabtree, A. (2003). Designing Collaborative Systems: A Practical Guide to Ethnography. London: Stringer-Verlag.

Elaluf-Calderwood, S. and Sørensen, C. (2006). Organizational Agility with Mobile ICT? The Case of London Black Cab Work. Butterworth-Heinemann.

Garfinkel, H. and Wieder,D.L. (1992) Two incommensurable, asymmetrically alternate technologies of social analysis, Text in Context: Contributions to Ethnomethodology (eds.Watson, G.and Seiler, S.M.), pp.175-206,New York: Sage.

Harris Interactive (2007). National Study Shows GPS Adoption Rates Relatively Low, but Offers Recommendations to Accelerate Market Penetration. http://www.harrisinteractive.com/NEWS/allnewsbydate.asp?NewsID=1241

Look, G., Kottahachchi, B., Laddaga, R., and Shrobe, H. (2005). A location representation for generating descriptive walking directions. In IUI '05: Proceedings of the 10th international conference on Intelligent user interfaces, pages 122-129, New York, NY, 
USA. ACM Press.

Perry, M., O'hara, K., Sellen, A., Brown, B., and Harper, R. (2001). Dealing with mobility: understanding access anytime, anywhere. ACM Trans. Comput.-Hum. Interact., $8(4): 323-347$.

O’Day, V. L., Bobrow, D. G., \& Shirley, M. (1996). The Social-Technical Design Circle. Proceedings of the ACM Conference on Computer-Supported Cooperative Work (CSCW'96) : 160-169.

Orlikowski, W. J. (1992b). Learning from Notes: Organizational Issues in Groupware Implementation. Proceedings of the Computer Supported Cooperative Work (CSCW'92) : 362-369.

Skok, W. (1999): Knowledge management: London taxi cabs case study. In Special Interest group on Computer Personnel Research Annual Conference. Proceeding oxf the 1999 SIGCPR Conference on Computer Personnel Research, New Orleans, Louisiana. ACM Press.

Suchman, L. (1987). Plans and Situated Actions. The Problem of Human-Machine Communication. Cambridge Univ. Press, Cambridge.

Suomela, R. and Lehikoinen, J. (2004). Taxonomy for visualizing location-based information. Virtual Reality, 8(2):71-82. 